\title{
Development and Analysis of Pre-Stressed Cable Roof with Stiffening Girder and Polymer Membrane Cladding
}

\author{
A.V. Chesnokov", V.V. Mikhailov``, I.V. Dolmatov` \\ The Faculty of Civil Engineering \\ Lipetsk State Technical University \\ Moskovskaya street 30, 398600 Lipetsk, Russian Federation \\ e-mail: andreychess742@gmail.com, web page: http://www.stu.lipetsk.ru \\ $\checkmark$ The Faculty of Civil Engineering \\ Lipetsk State Technical University \\ Moskovskaya street 30, 398600 Lipetsk, Russian Federation \\ e-mail:mmvv46@rambler.ru, web page: http://www.stu.lipetsk.ru \\ - The Faculty of Civil Engineering \\ Lipetsk State Technical University \\ Moskovskaya street 30, 398600 Lipetsk, Russian Federation \\ e-mail: dolmivv@gmail.com, web page: http://www.stu.lipetsk.ru
}

\begin{abstract}
Pre-stressed cable and membrane structures become an integral part of modern buildings. They have great potential in the field of civil engineering and in industrial construction as well.

The roof construction, considered in the research, consists of a flexible framework with a stiffening girder and an architectural membrane. The framework is a two-chord truss-like structure. The chords are made of pre-stressed steel cables, linked together by vertical struts. Flexible polymer membrane is attached to the top chord of the framework. It is tensioned by means of catenary and backstay cables. Horizontal thrust, induced by the chords, is equilibrated by the girder.

The girder and the struts of the truss are linked together by means of design clearances [1]. The clearance allows the strut to move freely a certain distance in the vertical direction. It prevents overstressing the girder, made of ordinary structural steel, and enhances the efficiency of highstrength steel cables. The girder, in turn, mitigates excessive deformations of the roof under nonuniform external loads.

Computational technique for static analysis of the roof is developed. Pre-stressing and operational stages are analyzed separately. External loads, uniformly distributed on the entire span and on the half of the span are taken into account. The membrane cladding is included into the structural model.

The technique allows to satisfy the limit state conditions. It provides the allowable cambering of the truss during the bottom chord tensioning and required deflection of the truss under the external load. Stiffness properties of the cables and the girder, required pre-stress values and the size of the design clearance are also given.
\end{abstract}

The results of the work are to be used for the preliminary design stage of pre-stressed cable roofs. The work contributes to the development of hybrid building constructions.

\section{REFERENCES}

[1] V.V. Mikhailov, A.V. Chesnokov and I.V. Dolmatov, "Pre-stressed cable truss with stiffening girder and design clearance: development and analysis", Softening the habitats. Sustainable innovation in minimal mass structures and lightweight architectures. Proc. of the TensiNet Symposium. P. 58-70 (2019). URL:

https://www.tensinet.com/files/Tensinet_Symposia/TensiNet_Softening-thehabitats_916.32456_def-1.pdf 